\title{
Nuevos desafíos democráticos de la universidad en contexto de la pandemia de COVID-19
}

\section{New democratic challenges of the university in the context of the COVID-19 pandemic}

\author{
Olga María Paredes Brítez ${ }^{a}$
}

\begin{abstract}
Resumen
Este ensayo tiene como objetivo reflexionar sobre los nuevos desafíos para el fortalecimiento democrático que enfrenta la Universidad como institución, en medio de la crisis producida por la pandemia de la COVID-19. Vivir esta pandemia en la era digital puede ser una amenaza o una oportunidad. La COVID-19 se presenta como una guerra, lo que pone en peligro el desenvolvimiento democrático de las relaciones. Los efectos del virus, se expanden no sólo a nivel físico, sino también mental y social. Reflexionamos a partir de algunos datos arrojados por un diagnóstico aplicado a 968 personas de la comunidad académica de la Universidad Metropolitana de Asunción, a efectos de conocer sus realidades en situación de COVID-19. Entre los resultados, encontramos insuficiente conocimiento para el cuidado de la salud mental, pero un alto deseo de participación y solidaridad en medio de la crisis. Uno de los nuevos desafíos que se presentan para la Universidad, tiene que ver con el desarrollo de procesos adaptativos a la crisis actual desde un enfoque democrático, en el que se promuevan los derechos humanos a la salud mental y a la participación, a través del fomento de la inclusión digital.
\end{abstract}

Palabras clave: COVID-19, universidad, democracia.

\begin{abstract}
This essay aims to reflect on the new challenges for the democratic strengthening facing the University as an institution, in the midst of the crisis caused by the COVID-19 pandemic. Living this pandemic in the digital age can be a threat or an opportunity. COVID-19 is presented as a war, jeopardizing the democratic development of relations. The effects of the virus expand not only physically, but also mentally and socially. We reflect on some data produced by a diagnosis applied to 968 people from the academic community of the Metropolitan University of Asunción, in order to know their realities in the situation of COVID-19. Among the results, we find insufficient knowledge of mental health care, but a high desire for participation and solidarity in the midst of the crisis. One of the
\end{abstract}

a Universidad Nacional de Asunción, Facultad de Ciencias Sociales, Paraguay.

Correspondencia a: olgaparedes92@gmail.com

Recibido:

18 de mayo de 2020

Aceptado:

30 de junio de 2020

Artículo publicado en acceso abierto bajo la Licencia Creative Commons.

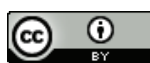

\section{Cita:}

Paredes Brítez, O. M. (2020). Nuevos desafíos democráticos de la universidad en contexto de la pandemia de COVID-19. Kera Yvoty: reflexiones sobre la cuestión social, 5 (número especial), 50-56. 
new challenges that arise for the University has to do with the development of adaptive processes to the current crisis from a democratic perspective, in which the human rights to mental health and participation are promoted, through the promotion of digital inclusion.

Keywords: COVID-19, university, democracy.

\section{Introducción}

Este trabajo reflexiona sobre algunos de los nuevos desafíos institucionales para la Universidad en el contexto actual de la pandemia de COVID-19. Históricamente, la Universidad es una institución de y para la democracia. Los desafíos institucionalesquese presentan, son esencialmente democráticos, ya que reivindican derechos humanos como el de la salud mental y el de la participación, puestos en situación de fragilidad en este contexto de la pandemia de COVID-19.

En primer término, revisamos algunas reflexiones sobre la realidad actual, que resultan relevantes para los análisis siguientes. Posteriormente, presentamos algunos datos cuantitativos arrojados por un estudio realizado a las/os integrantes de la comunidad académica de la Universidad Metropolitana de Asunción (docentes, funcionarias/os y estudiantes) en relación a sus perspectivas sobre la COVID-19. En base a esto, presentamos algunas conclusiones y propuestas que podrían contribuir a la discusión sobre los nuevos desafíos institucionales y democráticos de las universidades, de cara a la pandemia de COVID-19 y también a futuro.

\section{La primera pandemia con redes sociales}

La COVID-19 no es la primera pandemia del siglo XX. La primera pandemia del S. XX se suscitó a finales del 2002, en Guangzhou, China; cuando el SARS provocó 8422 casos y 916 muertes en 29 países de cinco continentes. Sin embargo, este nuevo coronavirus surgido desde finales del 2019, ha traído una pandemia con consecuencias nunca antes vistas en el mundo moderno globalizado (Bonilla, Villamil, Rabaan, \& Rodríguez, 2020).

La pandemia de COVID-19 se desarrolla en un tiempo de auge de las redes sociales y del más alto nivel de conectividad y accesibilidad a internet, nunca antes vistos en la historia de la humanidad. Tedros Adhanom, Director General de la Organización Mundial de la Salud (OMS), refirió como infodemia a la facilidad con la cual las imprecisiones repercuten y hasta se perpetúan en las redes sociales y en otros medios (Herrera, 2020). Esto permite a la pandemia de COVID-19 desarrollar peculiaridades propias en sus efectos sociales. Efectivamente, esta infodemia que acompaña a la COVID-19, pone en peligro constante a los sistemas de salud pública y por ende, a todas las personas. En efecto, uno de los retos más urgentes en el marco de esta pandemia es difundir información confiable y verificada (Herrera, 2020).

\section{Pandemia: guerra o democracia}

El fenómeno de la pandemia de COVID-19 es planteado discursivamente en diversas ocasiones como una guerra por las autoridades gubernamentales $\mathbf{o}$ incluso los medios de comunicación. Este planteamiento es peligroso según reflexiona Surian (2020), ya que en una guerra no se evalúan costos o resultados y se apuesta todo por un objetivo, por tanto ningún sacrificio se considerará excesivo. Este autor plantea que en una guerra todas las personas se vuelven víctimas: obedientes, dóciles y hasta resignadas. Las muertes se convierten en pérdidas indefectibles y los contagiados son discriminados en sus derechos por el solo hecho de haberse contagiado (Surian, 2020).

En esta coyuntura de desorden producida naturalmente por la crisis actual, se vuelve particularmente peligroso cualquier tipo discurso de corte autoritario, 
que resulta hasta una tentación frente al clima de inseguridad, poniendo en jaque a nuestro sistema democrático formal, de por sí ya muy fragilizado (Germani, 2017). Ante esto, necesitamos fortalecer las instituciones democráticas que promuevan desde sus diversos fines una ciudadanía activa que participe en procesos de transformación de comportamientos, hacia la generación de prácticas socio sanitarias de prevención actual y a futuro. Una de estas instituciones democráticas que debe ser fortalecida, es la universidad.

Otro discurso comúnmente escuchado es que el virus no reconoce entre ricos y pobres y que por tanto, no hace diferencias. Hay cierta verdad y cierta mentira en esa afirmación, que desemboca en una tergiversación peligrosa de la realidad. Es cierto que el virus como tal no discrimina, pero ciertos seres humanos sí, por efecto o con la excusa del virus. Como dice Butler (2020), en este contexto de la pandemia algunos tienden a jerarquizar unas vidas como más valiosas que otras. Es por esto que se hace necesario recurrir conceptualmente a la democracia y a una de sus instituciones emblemáticas: la universidad, a efectos de que sus fines últimos se renueven apuntando a la contención del fenómeno de la COVID-19. Este último, entendido no sólo como pandemia, sino también como el complejo conjunto de problemas socio políticos agravados que trae aparejados.

La cuarentena total es otra de las consecuencias principales a considerar de la pandemiadeCOVID-19. Lointrapersonalylo interpersonal reaparecen y se reencuentran en el hogar. Para Batthyany (2020) hay un retorno al hogar como un espacio donde se encuentran lo productivo: hacer teletrabajo desde la casa y lo reproductivo: las tareas domésticas, la educación de niñas y niños, además de su cuidado y el de adultas/os mayores, personas con discapacidad y/o enfermas/os. Esta es hoy la realidad de los hogares y dentro de ellos, de las personas que deben asumir la resolución de todas estas tareas, especialmente mujeres.
Sumemos a ese escenario complicado, la crisis económica manifiesta a través del desempleo y la reducción de los ingresos de las/os integrantes del hogar. Agravadas por el estrés pandémico, se suscitan conductas autoritarias reproducidas a través de discriminaciones y violencias en el hogar, que también son otro peligro para nuestra democracia pandémica.

\section{El derecho a la salud, física y mental}

Según Peng Kaiping, Director de Instituto de Psicología de la Universidad de Tsinghua, una de las acciones de contención de la COVID-19 ha sido atender llamadas de personas con síntomas de depresión y angustia, vinculados al trastorno de estrés post-traumático como consecuencia de la pandemia (Surian, 2020). Estamos en una pandemia que acentúa sus efectos en cada uno de los aspectos de las personas: psicológico, familiar, social, económico, cultural evidenciándolos como elementos constitutivos fundamentales del ser humano que antes no eran lo suficientemente ponderados en su relación de interdependencia.

Los efectos de la pandemia de COVID-19 no sólo se manifiestan en las/ os contagiadas/os, sino también en una innumerable cantidad de personas que sufre en su interior todos los problemas que trajo.

\section{Participar aun estando en cuarentena}

La gran pregunta es qué hacer ante esta pandemia que nos desafía. En Paraguay particularmente, debiéramos tener cierta institucionalización en la prevención de epidemias considerando la periodicidad del dengue. Organismos internacionales como la Organización Mundial de la Salud y la Organización Panamericana de la Salud recomiendan políticas sociales sostenibles y medidas legislativas para la prevención de epidemias; pero por sobre todo recomiendan la movilización de comunidades para la participación 
con el objetivo de generar cambios en el comportamiento de las personas (San Martín \& Prado, 2004).

Otra repregunta resultante es cómo generaresamovilizaciónsocialconsiderando la cuarentena, el distanciamiento y hasta el aislamiento requeridos. Pues para ello tendremos que servirnos de los medios digitales en auge de nuestro tiempo. Para San Martin y Prado (2004), la mera información no es suficiente para producir cambios en el comportamiento; se debe sustituir la información por la práctica y se debe dar una apropiación cultural de estas prácticas. Aunque aparentemente concreta, la solución no deja de ser compleja en su ejecución. Importante rescatar de todo esto, que debemos generar procesos institucionales y democráticos que promuevan la participación de la comunidad académica en la identificación de los problemas inmediatos y en la generación de alternativas de contención a los efectos de la pandemia de COVID-19. Reiteramos, todo esto desde un enfoque de derechos humanos reivindicando valores como la participación y la solidaridad, que son esencialmente valores de la democracia.

\section{Un estudio de caso}

En mayo de 2020, desde la Dirección de Extensión Universitaria de la Universidad Metropolitana de Asunción, realizamos un primer relevamiento para diagnóstico, a través de una auto encuesta para generar una línea de base, que permita identificar perspectivas psicológicas, sociales y económicas de las/ os integrantes de la comunidad académica, en contexto con la crisis producida por la pandemia de COVID-19. En la muestra aleatoria participaron 968 personas (estudiantes, docentes y funcionarios/as) que respondieron a un cuestionario con preguntas abiertas y cerradas, alojado a través del servicio Formularios de Google. Este primer relevamiento fue realizado en el marco de una investigación-acción que se encuentra desarrollando la institución, en pos de conocer realidades y ejecutar acciones con miras a la contención de los efectos de la COVID-19 en la comunidad académica. Compartimos algunos resultados con el objeto de su análisis y discusión en este documento.

Una de las preguntas trasladadas a las/os consultadas/os fue “ ¿Consideras que estarías vulnerable en cuanto a salud mental durante la cuarentena?"; a lo cual el 40,5\% respondió "no lo sé", el 24,8\% "no", el 23,5\% "sí, un poco" y por último, el 11,2\% contestó "sí, mucho". La mayoritaria respuesta de la muestra de estudio revela que el 40,5\% de las/os consultadas/os no estarían seguros de tener un equilibrio regular en esta la situación de crisis. También es posible que las personas no tengan un concepto claro de la salud mental y sus alcances, por lo que les resulta difícil contestar específicamente.

Otra consulta fue: “ ¿Cómo te sientes en general respecto a la COVID-19?", que arrojó como resultado que el 37,3\% está "con preocupación moderada o controlada", un 36,5 "con mucha preocupación", un $20,4 \%$ "con un poco de preocupación" y el 5,8\% "estable o sin cambios". Si sumáramos los segmentos de alta y moderada preocupación, nos encontramos con que el $73,8 \%$ de la muestra se encuentra dentro de este margen.

Ante el planteamiento "Después de la cuarentena, crees que la situación de la pandemia de COVID-19", un 46,4\% contestó "mejorará", un 30,5\% "permanecerá igual" y un $23,1 \%$ dijo que "estará peor". La mayoría de las personas tiene la perspectiva que la situación mejorará luego de la pandemia de la COVID-19, un 46,4\%. Sin embargo, desde otra perspectiva, si sumamos los resultados de las respuestas "igual" y "peor", suma un 53,6\% de la muestra. Por tanto, tenemos una mayoría de las personas con una visión optimista del futuro en un $46,4 \%$. Sin embargo, con una visión neutral o pesimista de la situación, suma un $53,4 \%$.

Por último, "En este contexto de la pandemia de COVID-19", un 46,8\% respondió "estoy dispuesto/a a dar algún apoyo $\mathrm{u}$ orientación a quien lo necesite, desde mi casa", un 37,4\% respondió "no 
requiero apoyo ahora mismo pero tampoco me siento en condiciones de otorgarlo", por último, un $15,8 \%$ dijo "necesito algún tipo de apoyo u orientación”. Esto nos revela que la mayoría de las/os consultadas/os están dispuestas/os a colaborar en generar y desarrollar mecanismos solidarios de apoyo y orientación al resto de la comunidad académica o de la sociedad en general.

\section{Reflexiones finales}

En la comunidad académica de estudio, el nivel de preocupación medio a alto es ampliamente mayoritario. Esto nos interpela institucionalmente como Universidad, a generar acciones de contención a uno de los efectos de la crisis, la salud mental, por medio de información y comunicación adecuadas. Un primer paso en ese proceso constituye esta línea de base. El siguiente es el desarrollo de enfoques integrales de trabajo adaptados a esta nueva realidad que nos envuelve. Estos enfoques deben contemplar los múltiples aspectos de la vida humana y social, todos relevantes, que hacen a la vida de las/os miembros de la comunidad académica. A propósito, antes de esta crisis, aspectos como la salud mental no formaban parte de loacadémico; pero hoy tomamos conciencia plena de que el abordaje de estos aspectos es de relevancia para el cumplimiento de los fines académicos, tanto personales como institucionales. Efectivamente, según los datos arrojados por este diagnóstico, la comunidad académica requiere del conocimiento y fomento de prácticas de cuidado de la salud mental.

Por citar, desde extensión universitaria, se podrían trabajar proyectos que promuevan la toma de conciencia sobre la salud mental a nivel personal y colectivo en este contexto de crisis. Estas iniciativas pueden generarse en dos niveles, por un lado formación y reflexión y por el otro, contención. Asimismo, es importante que en todos los proyectos de extensión universitaria, especialmente aquellos que involucren un contacto directo con personas o poblaciones afectadas por esta crisis, se incorporen momentos en las etapas del proyecto, donde pueda valorarse y cuidarse la salud mental de las y los integrantes del proyecto.

En los resultados vistos, la mayoría de la comunidad académica tiene una visión optimista del futuro post pandemia. Anima que la comunidad académica está motivada por la idea de un futuro mejor para todas y todos, lo cual es posible que repercuta positivamente en diversos aspectos, ya que la esperanza y el optimismo son valores fundamentales para el desarrollo. Sin embargo, si sumamos a los segmentos que tienen una visión neutral o pesimista del futuro post pandemia, resulta un porcentaje importante. Siguiendo la idea de párrafos anteriores, es necesario en primer término desarrollar los espacios de promoción de salud mental; así como profundizar respecto a otras circunstancias macro o micro sociales que están produciendo perspectivas pesimistas en las personas, para generar posteriormente a su identificación, acciones acordes.

Hay una correlación entre el porcentaje mayoritario que tiene una visión optimista del futuro post pandemia y el que también está dispuesto a dar apoyo $u$ orientación a otras/os que los necesiten, ya sea por su predisposición personal o sus condiciones materiales. Es de vital importancia que ese capital humano y social con deseos de participar sea potenciado para generar acciones positivas tanto en los hacedoras/es de la solidaridad como en las/os que la reciben. El deseo de participación está presente en la comunidad académica, aunque poco operativo en los términos tradicionales, las reuniones y las movilizaciones ya no son posibles como las conocíamos. Pero esta pandemia es la primera en la historia del mundo que también se vivencia desde las redes sociales. Es momento de animarnos a promover un derecho humano de cuarta generación: el derecho a la inclusión digital; fomentar la conectividad y accesibilidad a internet de las personas para crear nuevas formas de participar en esta etapa histórica 
de la democracia. Generamos mecanismos digitales para participar desde un enfoque democrático, o volvemos a anacronismos como la idea de que vivimos recluidos en medio de una guerra, que es en todo el mundo.

Estos son algunos de los nuevos desafíos se presentan. Democracia o guerra, salud o pandemia, participación o silencio. En esta cuarentena, el derecho a la inclusión digital se equipara al de la libertad de expresión. La Universidad entendida como una institución de y para la democracia, debe actuar en consecuencia con estas nuevas realidades.

Esta pandemia ha acentuado las desigualdades. Las perspectivas pesimistas del estudio de caso están basadas en limitaciones materiales generales $y$ particulares, que se presentan agravadas por la pandemia. En contrapartida, nos encontramos con una importante predisposición optimista hacia la visión de un futuro post pandemia; una esperanza de cambio, que podemos canalizar en acciones innovadoras que fomenten un desarrollo integral y desfragmentado de las personas y de instituciones como la universidad. Los efectos de la COVID-19 no son sólo en el ámbito físico o material, sino también en lo mental y aún desde el confinamiento las personas necesitan encontrarse y participar, con inclusión digital.

Grandes pensadores contemporáneos han presentado de forma dicotómica sus perspectivas post pandemia. Zizek y otros la presentan como una utopía, en tanto que Han y otros más como una distopía. Coincidimos con Zizek (2020) en que es triste que tenga que venir un virus para hacernos dar cuenta que necesitamos un cambio radical. Concordamos con Han (2020) en que no habrá un cambio per sé luegodeesta pandemia, a menosquepartade nosotros mismos. Somos nosotros quienes debemos restringir el capitalismo salvaje y destructivo y sus efectos en la medida que lo reproducimos. Necesitamos repensarnos a nosotros y a las instituciones de las que somos parte. Estos son solo algunos nuevos desafíos institucionales que debe superar la universidad, para posicionarse desde la democracia y los derechos y no desde la guerra y la enfermedad.

\section{Referencias}

Batthyány, K. (2020). Miradas latinoamericanas a la educación en tiempos de pandemia. Consejo Latinoamericano de Ciencias Sociales (CLACSO). https://www.clacso. org/miradas-latinoamericanasa-la-educacion-en-tiempos-depandemia-2/

Bonilla, D., Villamil, W., Rabaan, A., \& Rodriguez, A. (2020). Una nueva zoonosis viral de preocupación global: COVID-19, enfermedad por coronavirus 2019. Revista IATREIA, 33(2), 107-110.

Butler, J. (2020). El capitalismo tiene sus límites. En P. Amadeo (Ed.), Sopa de Wuhan: Pensamiento Contemporáneo en tiempos de pandemias (pp. 59-68). Editorial ASPO (Aislamiento Social Preventivo y Obligatorio).

Germani, G. (2017). Democracia y autoritarismo en la sociedad moderna. En: Fernando Calderón Gutiérrez (Comp.) Los límites de la democracia, 1 (pp. 13-52). CLACSO.

Han, B. (2020). La emergencia viral y el mundo del mañana. En P. Amadeo (Ed.), Sopa de Wuhan: Pensamiento contemporáneo en tiempos de pandemias (pp.97-112). Editorial ASPO (Aislamiento Social Preventivo y Obligatorio).

Herrera, D. (2020). Cómo enfrentar el COVID-19. Revista Práctica familiar rural, 5 (1).

San Martin, J., \& Pardo, M. (2004). Percepción del riesgo y estrategias de comunicación social sobre el dengue en las Américas. Revista Panamericana de Salud Pública, 15(2), 135-139.

Surian, A. (2020). Educación, salud pública y gestión de las epidemias. ¿Qué lecciones nos está dejando? Consejo Latinoamericano de Ciencias Sociales 
(CLACSO). https://www.clacso.org/ educacion-salud-publica-y-gestionde-las-epidemias-que-lecciones-nosesta-dejando/
Editorial ASPO (Aislamiento Social Preventivo y Obligatorio).

Zizek, S. (2020). El coronavirus es un golpe al capitalismo a lo Kill Bill. En P. Amadeo (Ed.), Sopa de Wuhan: Pensamiento contemporáneo en tiempos de pandemias (pp. 21-28).

\section{Sobre la Autora}

Olga María Paredes Brítez

Docente Técnico de la Facultad de Ciencias Sociales (UNA). Directora de Extensión de la Universidad Metropolitana de Asunción. Abogada y Trabajadora Social. Ha cursado maestrías en Ciencias Sociales y en Project Management. 